\title{
Mechanical Properties and Acoustic Emission Characteristics of Karst Limestone under Uniaxial Compression
}

\author{
Jianxun Chen $\left(\mathbb{D},{ }^{1}\right.$ Qingsong Wang $\mathbb{D}^{1},{ }^{1}$ Jiaqi Guo $\mathbb{D}^{1,},{ }^{1,2}$ Yanbin Luo ${ }^{D},{ }^{1}$ Yao Li, ${ }^{1}$ \\ Qin Liu ${ }^{1}{ }^{1}$ and Hongyu Wang ${ }^{3}$ \\ ${ }^{1}$ School of Highway, Chang'an University, Xi'an, Shaanxi 710064, China \\ ${ }^{2}$ School of Civil Engineering, Henan Polytechnic University, Jiaozuo, Henan 454000, China \\ ${ }^{3}$ Shaanxi Provincial Transport Planning Design and Research Institute, Xi'an, Shaanxi 710068, China
}

Correspondence should be addressed to Qingsong Wang; wangqs_1989@163.com

Received 2 February 2018; Revised 24 April 2018; Accepted 16 May 2018; Published 12 July 2018

Academic Editor: Hongchao Kou

Copyright ( 2018 Jianxun Chen et al. This is an open access article distributed under the Creative Commons Attribution License, which permits unrestricted use, distribution, and reproduction in any medium, provided the original work is properly cited.

Firstly, I-RPT ultrasonic detector was used to test the wave velocity of karst limestone with different initial microstructure and water content. Then, RMT-150B rock testing machine and DS2-16B acoustic emission system were used to test the acoustic emission (AE) under uniaxial compression. Mechanical properties and AE characteristics were obtained during rock failure. The detailed relationship between stress-strain and AE characteristics was studied in this paper. Research results indicated the following: (1) For samples with many primary fissures and defects, wave velocity in dry state was larger than that in its natural state. From natural state to saturated state, the wave velocity tended to increase. For samples with good integrity, wave velocity increased with increasing of water content. (2) In the dry state, the samples presented tension failure. In saturated state, the samples presented tension-shear failure. For samples with cracks and good integrity, samples showed brittle failure. For samples with many corrosion pores which showed ductile damage under natural and saturated state, the spalling phenomenon was enhanced under saturated state. (3) With increasing of water content, the peak stress and AE peak reduced dramatically. In brittle failure, AE peak could be considered a sign of failure. In ductile failure, AE activity decreased gradually with the decrease of stress. (4) The mechanical properties and AE characteristics corresponding to four main fracture propagation types were also discussed.

\section{Introduction}

China has the most widely distributed karst area in the world. The distribution area of soluble rock in China is mainly located in the southwest, total area is about $3,400,000 \mathrm{~km}^{2}$ (Figure 1), among which the exposed carbonate area reaches $910,000 \mathrm{~km}^{2}[1,2]$. The development of Western China is an important strategy for China's economic development, in which transportation construction is one of Western China's most important economic policies: many highway and railway tunnels have been built in recent years [3-6]. However, due to the concealment of tunnel engineering, an increasing number of geological disasters have occurred during the tunnel construction [7-10]. Karst disasters, such as water and mud inrush, have become the most serious geological hazards during tunnel constructions in Southwest China (Figure 2)
[11-18]. The hazards are closely related to rock properties. Study on the mechanical properties of rocks provides the parameters for engineering design, which helps prevent and decrease geologic hazards [19-23].

The failure of brittle rock is a process of internal microcrack generation, expansion, and coalescence, which can cause stress relaxation and energy release, resulting in the acoustic emission (AE) phenomenon [24-26]. AE technique can collect and analyze acoustic waves during rock failure. AE characteristic can well reflect the compressive deformation and damage evolution process of rocks, which can thus help scholars understand rock failure mechanism and the inherent condition changes [27-29]. Commonly used $\mathrm{AE}$ parameters include event rate, ring-down counts, energy rate, amplitude, average of signal level (ASL), and frequency. 


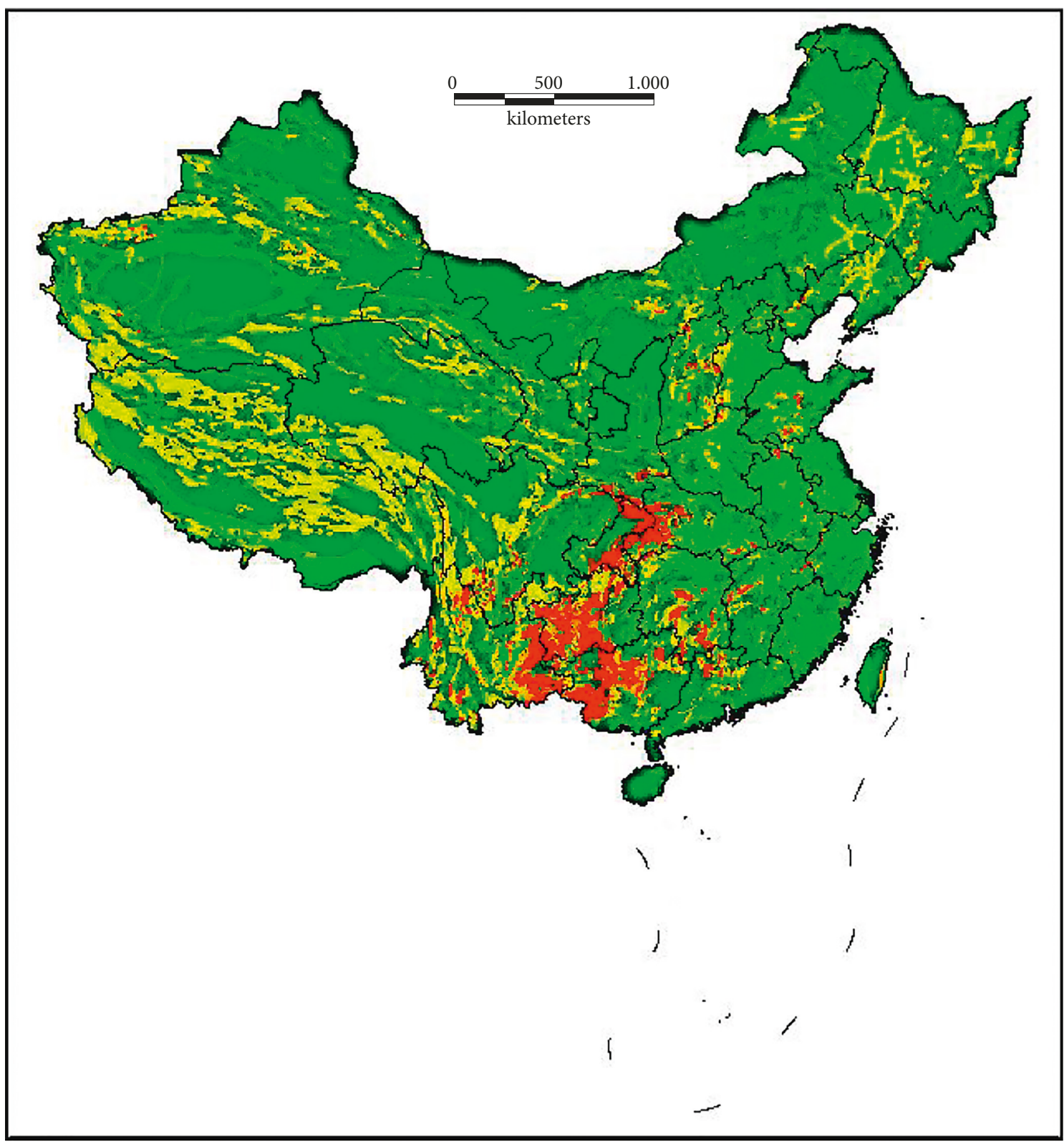

Karst area with extreme hazard

Karst area with hazard

Karst area with moderate hazard

FIgure 1: The karst region distribution in China.

Rock generally contains various microcracks, fissures, pores, joints, and other defects. It always contains water in nature. The defects and water have obvious effects on the mechanical properties and $\mathrm{AE}$ characteristics of rocks [30-33]. Numerous studies have been conducted on rocks or rock-like materials with preexisting or native fissures under uniaxial compression. Results of these studies indicate that the geometry of preexisting flaws affect fractures initiation and coalescence behavior, whose quantity and angle significantly influence the mechanical properties and $\mathrm{AE}$ characteristics of a specimen [34-37]. Water content also has an important impact on the AE emission characteristics in the sample failure process. Water has an obvious softening effect on the primary fissures in rock samples. Moreover, pore pressure is inferred to take part in the sample deformation and promotes fracture network generation [38-40]. These cause the promoting plastic behaviour and the dissipation of internal energy. From the macroscopic view, the strength and $\mathrm{AE}$ activity will decrease [41-43].

Few studies have investigated the mechanical properties and $\mathrm{AE}$ characteristics of rock by considering the coupling effect of initial microstructure and water content. In the present research, $\mathrm{AE}$ monitoring tests under uniaxial compression were conducted on karst limestone specimens 


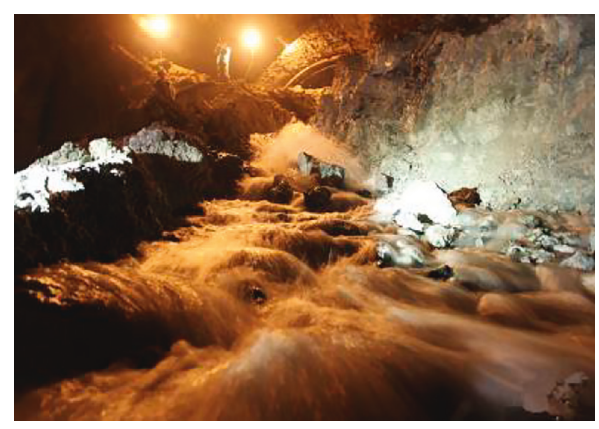

(a)

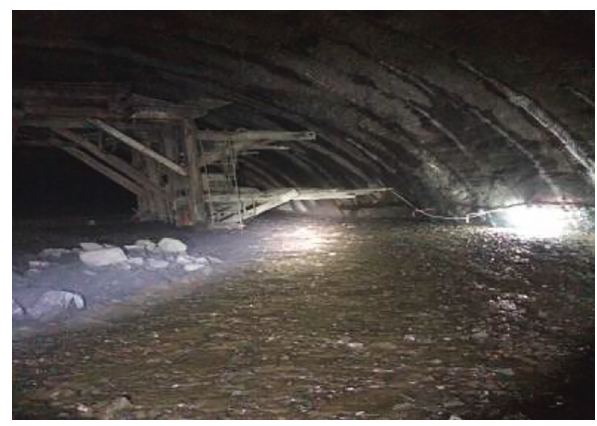

(c)

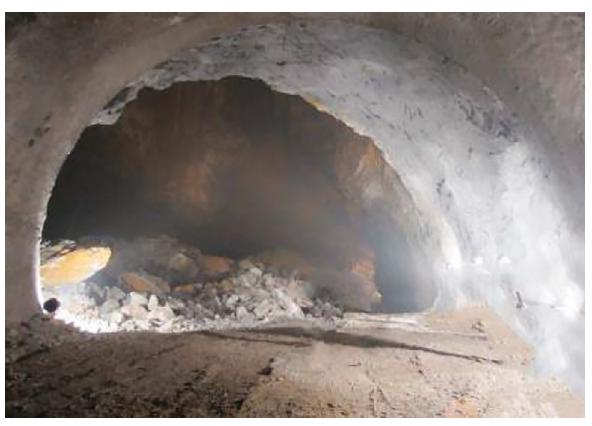

(b)

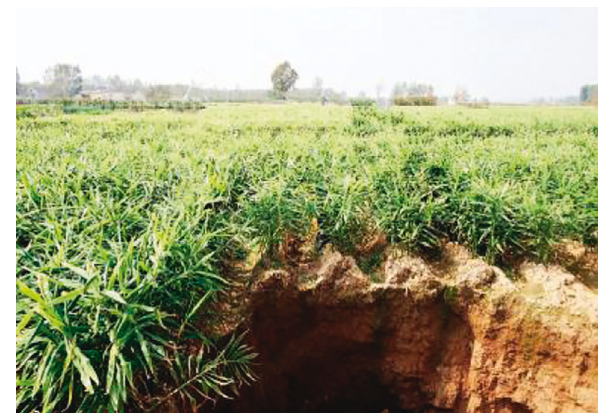

(d)

Figure 2: The common geological disasters of tunnel construction in karst region. (a) Water inrush. (b) Cave collapse. (c) Mud inrush. (d) Ground collapse.

by evaluating the coupling effects of three types of initial microstructure (cracks, corrosion pores, and integral) and three levels of water saturation (dry, natural, and saturated). Results of the $\mathrm{AE}$ tests revealed the relationship between limestone failure and AE parameters, which will help scholars further understand the rock failure mechanism and propose an indicator that can be used to predict rock failure. Thus, this study can significantly aid in monitoring and evaluating the stability of rock mass engineering.

\section{Experimental Methods}

2.1. Rock Sample and Preparation. Karst limestone was from three sections of the Qiyue-shan Tunnel of LichuanWanzhou Highway construction sites in Hubei Province, China. The tunnel area lies in the southwest fold mountain zone of Hubei Province and is a typical karst area. The cover layer mainly consists of Quaternary silty clay, which is from the accumulation of ancient landslide. The bedrock is thicklayered limestone of Jialing River formation, Lower Triassic.

Fresh rocks without obvious cracks were selected in the construction site and wrapped with multilayer preservative films. The rocks were then prepared as $\Phi 50 \mathrm{~mm} \times 100 \mathrm{~mm}$ cylindrical samples. As shown in Figure 3, group A samples contained obvious cracks and group B samples contained numerous corrosion pores. Group C samples were relatively complete in structure, without obvious defects. Each group is divided into three sets according to their water content. The samples of the first set were sufficiently dried, the second set was in its natural state, and the third set consisted of water-saturated specimens. The first and third sets of samples were placed in an electric thermostatic drying oven to maintain constant-temperature drying for $24 \mathrm{~h}$ at $110^{\circ} \mathrm{C}$. For the third set, after drying, the samples were saturated by vacuum pumping immersion method. The vacuum pressure was kept at $100 \mathrm{kPa}$, and the pumping time was $6 \mathrm{~h}$. Each test was repeated three times to reduce test errors. Therefore, 9 sets of 27 experiments were conducted in this study.

2.2. Equipment and Loading Condition. Figure 4 shows the testing equipment. The nonmetallic I-RPT ultrasonic detector was used to record the speed of pressure wave ( $\mathrm{P}$ wave) and shear wave (S-wave). The P-wave transducer frequency was $50 \mathrm{KHz}$, the $\mathrm{S}$-wave transducer frequency was $150 \mathrm{KHz}$, the sampling length was 1024 , and the sampling period was $0.4 \mu \mathrm{s}$.

The loading equipment used in this study was the RMT150B computer-controlled triaxial testing machine, which can provide $1000 \mathrm{kN}$ maximum axial pressure and conduct uniaxial or triaxial loading tests. This study used the displacement control mode for the test process, which was $0.002 \mathrm{~mm} / \mathrm{s}$.

The DS2-16B AE detection system was used for real-time monitoring of $\mathrm{AE}$. To eliminate the effect of noise on the $\mathrm{AE}$ test, the threshold was set to $50 \mathrm{mV}$ and the preamplifier gain was set $40 \mathrm{~dB}$. Two AE sensors were arranged symmetrically on the sides of the sample, and the contact face was coupled with Vaseline.

\section{Mechanical Properties of Karst Limestone}

3.1. Physical Parameters of the Samples. The physical parameters of the rock samples are shown in Table 1. As the 


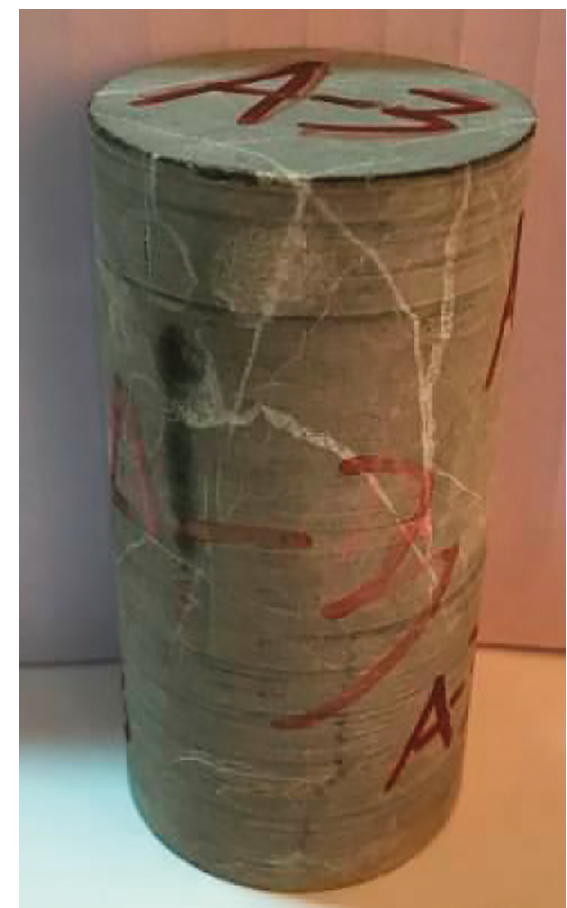

(a)

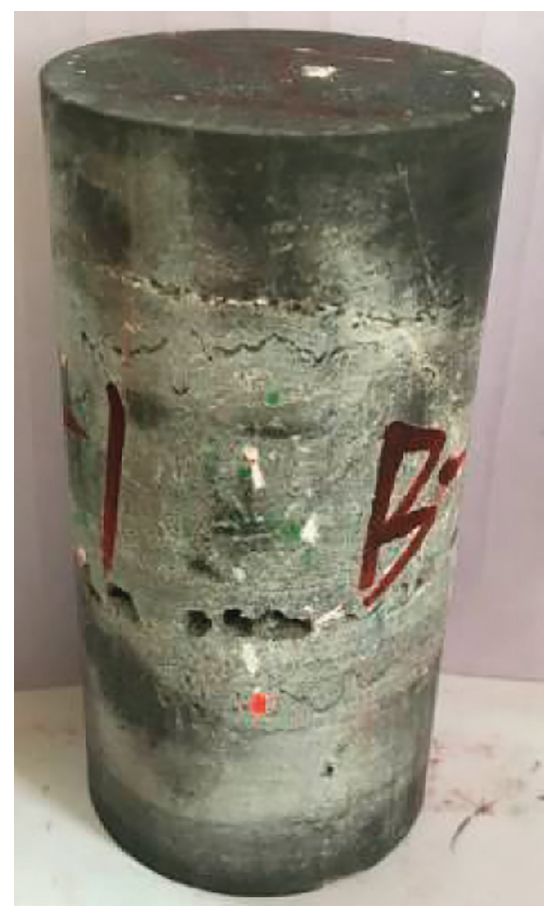

(b)

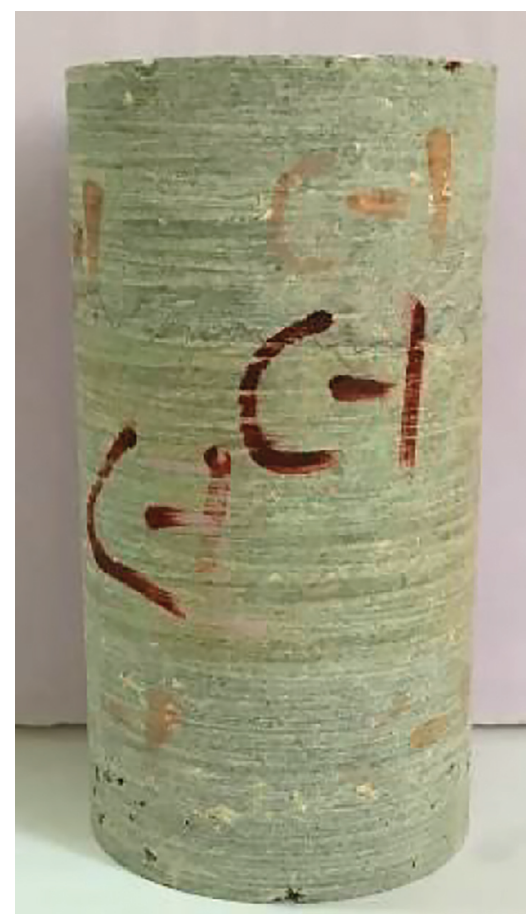

(c)

FiguRE 3: Limestone rock samples. (a) Group A. (b) Group B. (c) Group C.

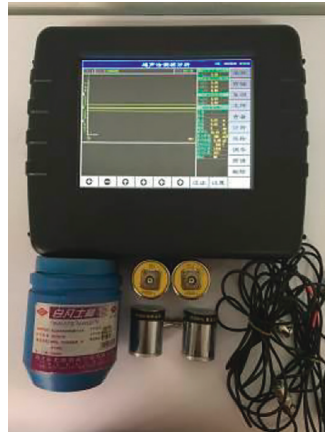

(a)

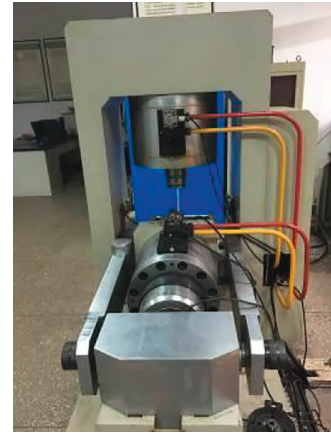

(b)

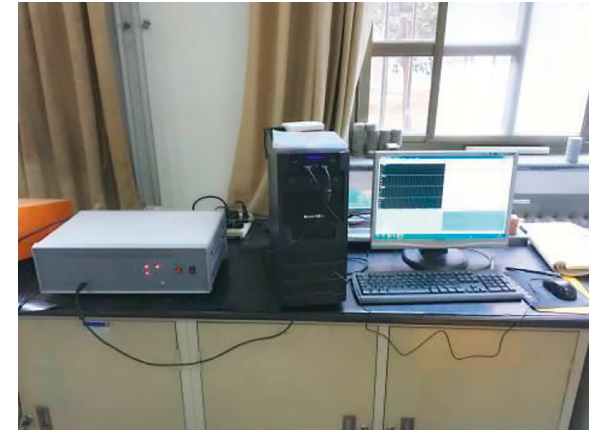

(c)

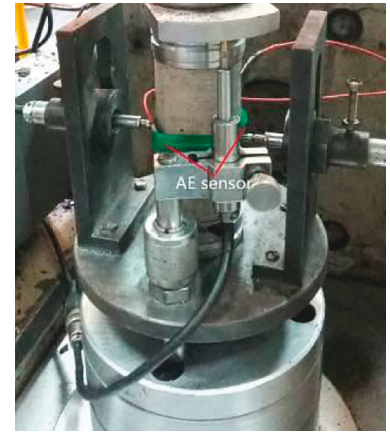

(d)

Figure 4: Test equipments. (a) I-RPT. (b) RMT-150B. (c) DS2-16B AE monitor system. (d) AE sensors arrangement.

water content of the natural state cannot be obtained directly, the average values of the same group samples in the natural state are presented.

According to Figure 5, for samples with many primary fissures and defects (group A and B), the wave velocity in dry state was larger than that in its natural state. From natural state to saturated state, the wave velocity tended to increase. This outcome was attributed to the various defects on the rock samples. After water absorption, the water molecule could weaken the connecting capacity between particles, part of the water was adsorbed by the defects, and water membranes were formed. The water membranes could cause the refraction and reflection of elastic wave, which caused decrease of wave velocity. With increasing of water content, the defects were saturated and the rock matrix and defects were connected well by the water. This effect caused the wave velocity to go straight through the rock without refraction and reflection, which caused the increase of wave velocity. For group C, because the cracks were not obvious, the water membranes reflection had almost no effect on the wave, and the wave velocity increased with the increase of water.

\subsection{Mechanical Properties of Karst Limestone under Uniaxial} Compression. According to previous studies, the failure process of brittle rock can be generally divided into five stages: crack closure, elastic deformation, fracture initiation and stable growth, fracture damage and unstable growth, and failure and post peak [44-46]. According to the experimental results, the stress-strain curves of karst limestone samples under uniaxial compression were showed in Figures 6-8. 
TABLE 1: List of rock samples physical parameters.

\begin{tabular}{|c|c|c|c|c|c|c|}
\hline Group & State & Number & Density $/\left(\mathrm{g} / \mathrm{cm}^{3}\right)$ & $\mathrm{Vp} /(\mathrm{m} / \mathrm{s})$ & $\mathrm{Vs} /(\mathrm{m} / \mathrm{s})$ & Water content (\%) \\
\hline \multirow{9}{*}{ Group A } & \multirow{3}{*}{ Dry } & A-1 & 2.680 & 5240 & 2868 & 0.00 \\
\hline & & A-2 & 2.688 & 5403 & 3727 & 0.00 \\
\hline & & A-3 & 2.672 & 4783 & 2794 & 0.00 \\
\hline & \multirow{3}{*}{ Natural } & A- 4 & 2.668 & 4419 & 2644 & - \\
\hline & & A-5 & 2.688 & 4518 & 2641 & 0.16 \\
\hline & & A-6 & 2.685 & 4848 & 2744 & - \\
\hline & \multirow{3}{*}{ Saturated } & A-7 & 2.674 & 5207 & 3317 & 0.27 \\
\hline & & A- 8 & 2.675 & 5199 & 3006 & 0.28 \\
\hline & & A-9 & 2.685 & 5456 & 3118 & 0.30 \\
\hline \multirow{9}{*}{ Group B } & \multirow{3}{*}{ Dry } & B-1 & 2.682 & 4652 & 2665 & 0.00 \\
\hline & & B-2 & 2.687 & 5085 & 2960 & 0.00 \\
\hline & & B-3 & 2.690 & 4894 & 2908 & 0.00 \\
\hline & \multirow{3}{*}{ Natural } & B-4 & 2.698 & 4688 & 2681 & - \\
\hline & & B-5 & 2.672 & 4430 & 2680 & 0.18 \\
\hline & & B-6 & 2.734 & 4535 & 2524 & - \\
\hline & \multirow{3}{*}{ Saturated } & B-7 & 2.678 & 5085 & 2930 & 0.86 \\
\hline & & B-8 & 2.698 & 4970 & 2890 & 1.01 \\
\hline & & B-9 & 2.673 & 5109 & 3015 & 1.08 \\
\hline \multirow{9}{*}{ Group C } & \multirow{3}{*}{ Dry } & C-1 & 2.741 & 3137 & 1854 & 0.00 \\
\hline & & $\mathrm{C}-2$ & 2.727 & 3706 & 2159 & 0.00 \\
\hline & & C-3 & 2.701 & 3592 & 2115 & 0.00 \\
\hline & \multirow{3}{*}{ Natural } & C-4 & 2.804 & 4202 & 2469 & - \\
\hline & & C-5 & 2.684 & 4327 & 2678 & 0.14 \\
\hline & & C-6 & 2.770 & 4102 & 2305 & - \\
\hline & \multirow{3}{*}{ Saturated } & C-7 & 2.755 & 5870 & 3567 & 0.26 \\
\hline & & C-8 & 2.755 & 5810 & 4536 & 0.28 \\
\hline & & C-9 & 2.792 & 5892 & 3607 & 0.31 \\
\hline
\end{tabular}

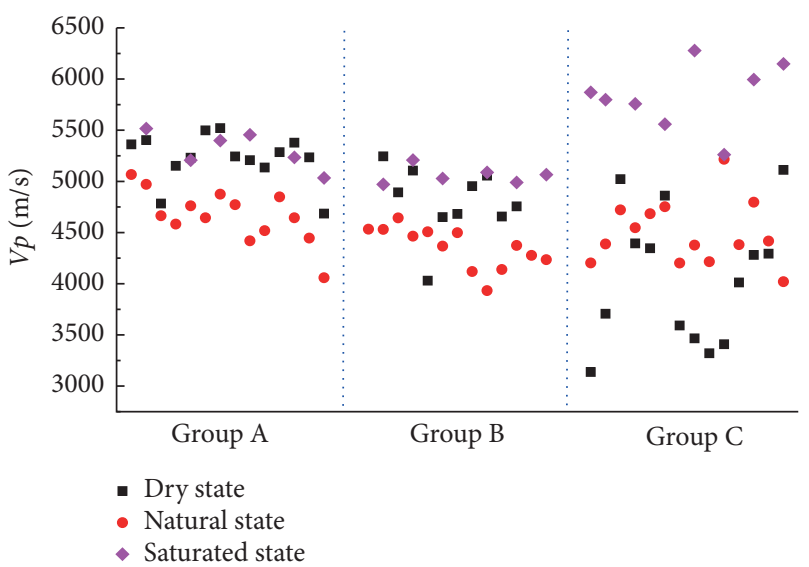

(a)

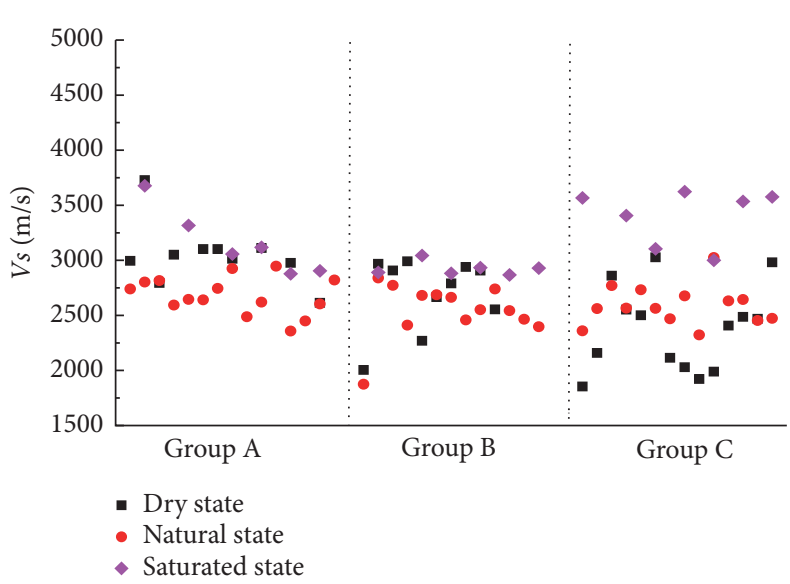

(b)

Figure 5: Wave velocity of limestone samples. (a) P-wave. (b) S-wave.

The samples under the dry state showed obvious elasticbrittle failure. No plastic deformation occurred before peak strength and after the compaction stage and linear elastic deformation stage, and the stress dropped suddenly to zero with ringing sound of rupture. For the group A samples under natural and saturated state, a small part of plastic deformation appeared near peak strength and then damaged rapidly. For the group B samples under natural and saturated state, an obvious plastic deformation existed before peak strength. After peak strength, the stress decreased gradually and showed ductility damage. For the group C samples under natural and saturated state, the stress dropped sharply after compaction stage, linear elastic deformation stage, and plastic deformation stage.

Tables 2-4 show the peak strength ratio of the limestone samples with different water content. For Group A, the ratio was $1: 0.93: 0.83$. For Group C, it was $1: 0.88: 0.70$. The dry limestone sample had the highest strength, its peak strength decreased gradually with the increase in water content. Meanwhile, the influence of water content on the axial strain 


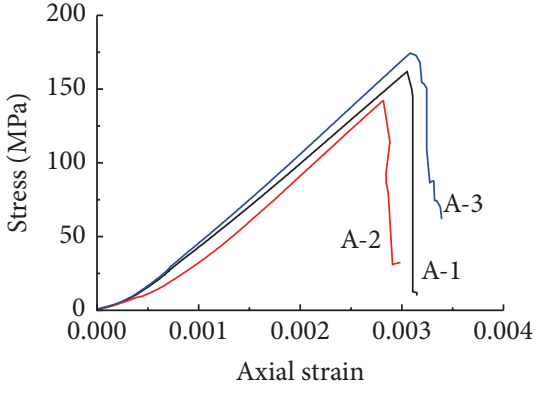

(a)

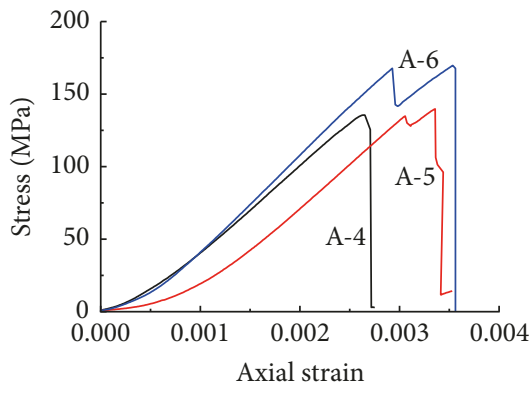

(b)

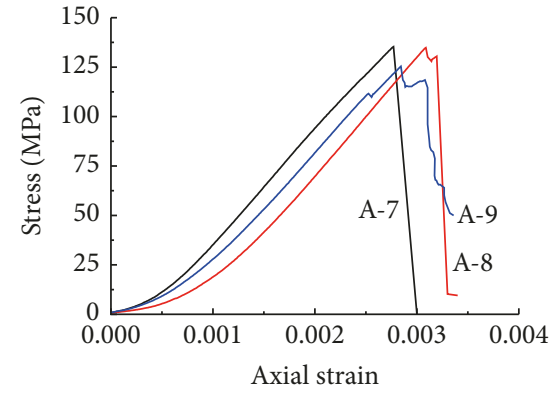

(c)

Figure 6: The stress-strain curves of group A samples with different water content. (a) Group A, dry state. (b) Group A, natural state. (c) Group A, saturated state.

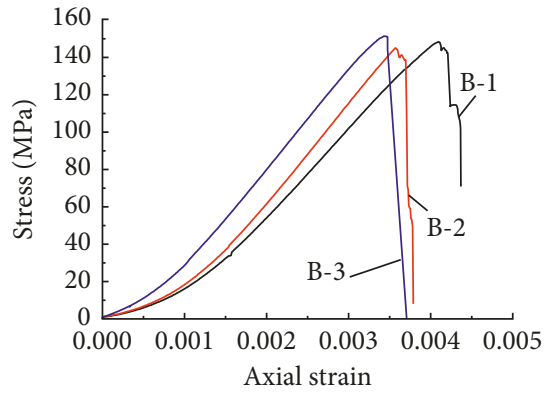

(a)

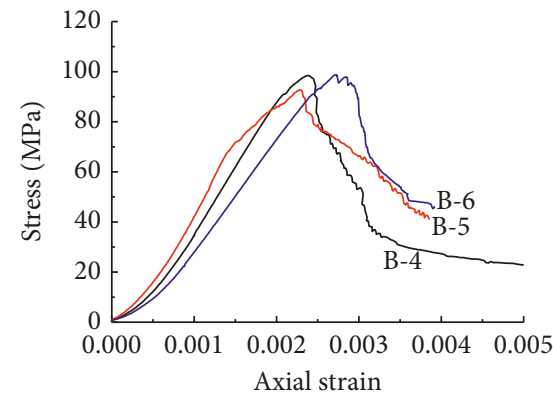

(b)

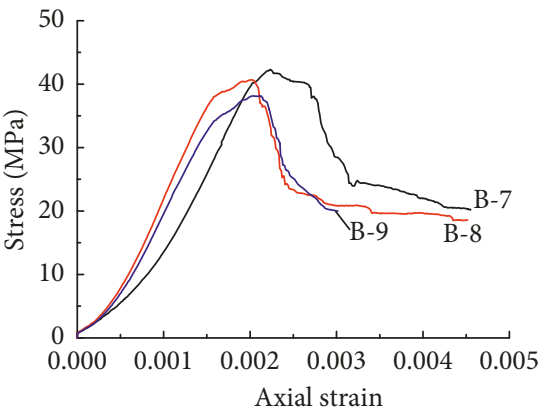

(c)

Figure 7: The stress-strain curves of group B samples with different water content. (a) Group B, dry state. (b) Group B, natural state. (c) Group B, saturated state.

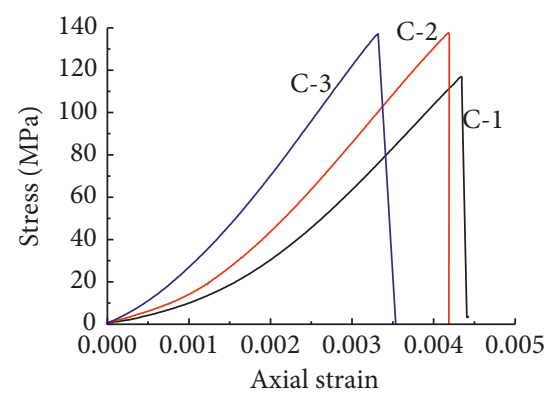

(a)

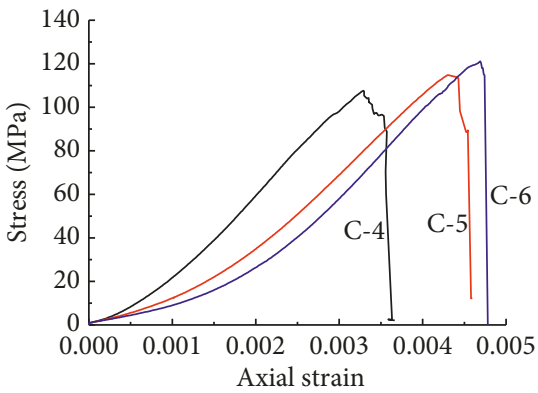

(b)

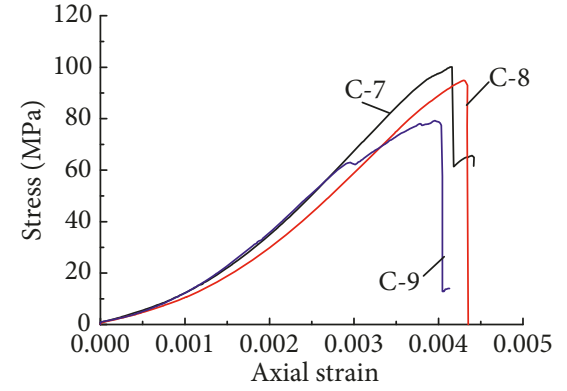

(c)

FiguRE 8: The stress-strain curves of group C samples with different water content. (a) Group C, dry state. (b) Group C, natural state. (c) Group C, saturated state.

and total strain at peak stress was not obvious. For Group B, the ratio was $1: 0.65: 0.29$, and the water-softening effect was reinforced because of the poor initial microstructure.

Figures 9-11 showed the fracture modes of rock samples with different initial microstructure and water content. For group $\mathrm{A}$, the fracture modes showed tension failure with many vertical fractures and sheet debris. In saturated condition, the samples presented tension failure with local shear failure. For group B, both tension and spalling failure existed, as many vertical and horizontal fractures were observed near the corrosion pores. Under vertical loading, stress concentration appeared at the horizontal sides of corrosion pores, which caused fractures to develop and coalescence at the horizontal direction. The horizontal fractures were also irregular. With increasing of water content, the spalling of blocks likewise increased. For group $\mathrm{C}$, the fracture modes under dry and natural state mainly belonged to tension failure, and local shear failure likely 
TABLE 2: Strength of group A samples.

\begin{tabular}{lcccccccc}
\hline State & \multicolumn{9}{c}{ Peak strength $(\mathrm{MPa})$} & \multicolumn{3}{c}{ Average value (MPa) } \\
\hline Dry & A-1 & 161.8 & A-2 & 142.1 & A-3 & 174.4 & 159.4 & 1 \\
Natural & A-4 & 135.5 & A-5 & 139.7 & A-6 & 167.8 & 147.7 & 0.93 \\
Saturated & A-7 & 135.3 & A-8 & 134.8 & A-9 & 125.4 & 131.8 & 0.83 \\
\hline
\end{tabular}

TABLE 3: Strength of group B samples.

\begin{tabular}{lcccccccc}
\hline State & \multicolumn{3}{c}{ Peak strength $(\mathrm{MPa})$} & \multicolumn{3}{c}{ Average value (MPa) } & Relative ratio \\
\hline Dry & B-1 & 148.4 & B-2 & 145.1 & B-3 & 151.4 & 148.3 & 96.7 \\
Natural & B-4 & 98.5 & B-5 & 92.9 & B-6 & 98.7 & 4 & 0.65 \\
Saturated & B-7 & 42.3 & B-8 & 40.7 & B-9 & 45.5 & 42.8 & 0.29 \\
\hline
\end{tabular}

TABLE 4: Strength of group C samples.

\begin{tabular}{|c|c|c|c|c|c|c|c|c|}
\hline State & & & eak s & h $(\mathrm{MPa}$ & & & Average value $(\mathrm{MPa})$ & Relative ratio \\
\hline Dry & C-1 & 116.9 & $\mathrm{C}-2$ & 137.7 & $\mathrm{C}-3$ & 137.1 & 130.6 & 1 \\
\hline Natural & C-4 & 107.6 & C-5 & 114.8 & C-6 & 121.1 & 114.5 & 0.88 \\
\hline Saturated & $\mathrm{C}-7$ & 100.1 & C-8 & 94.9 & C-9 & 79.2 & 91.4 & 0.70 \\
\hline
\end{tabular}

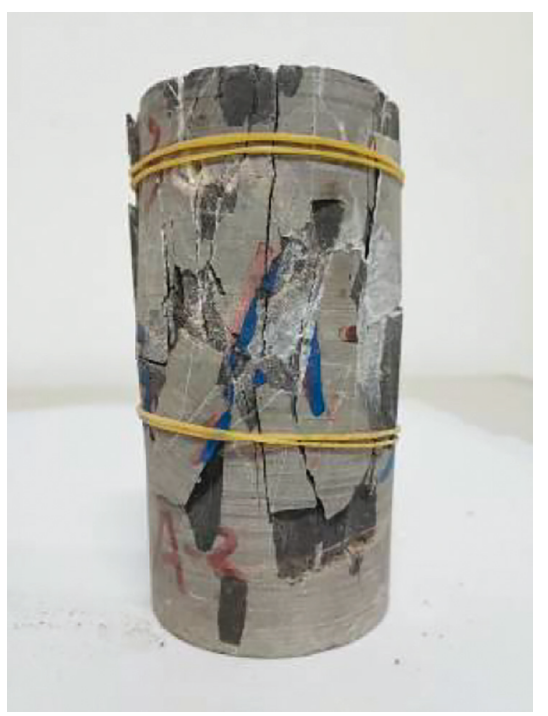

(a)

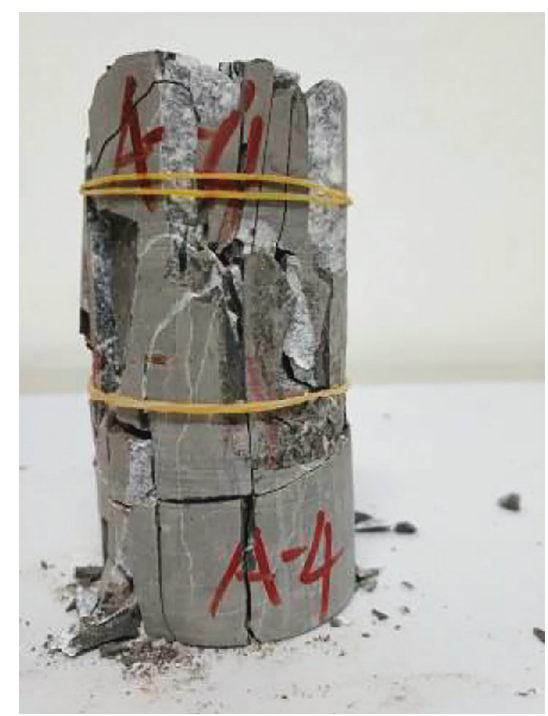

(b)

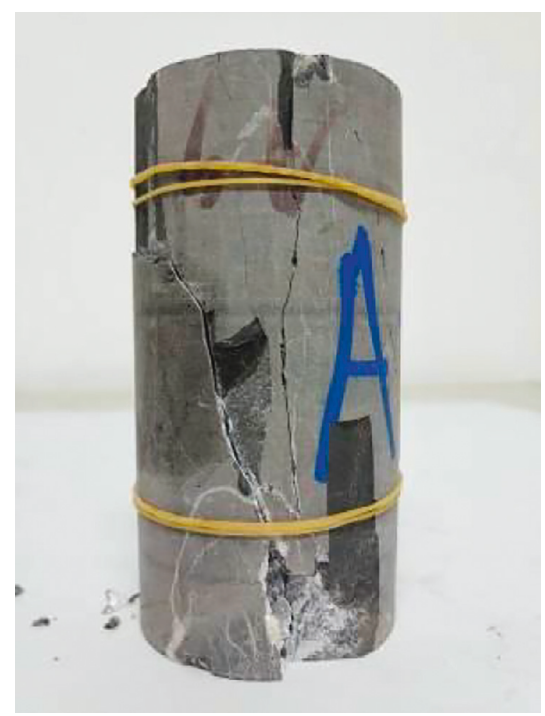

(c)

Figure 9: Failure modes of group A. (a) Dry state. (b) Natural state. (c) Saturated state.

existed for the natural state. Under the saturated condition, the X-shape or Y-shape fractures, which showed tensionshear mixed failure, were clearly observed.

\section{AE Characteristics of Karst Limestone}

4.1. Selection of AE Parameters. AE parameters include ringdown counts, cumulative ring-down counts, energy rate and cumulative energy, acoustic frequency, hit number, and amplitude. AE count is defined as the number of times the acoustic emission signal exceeds a preset threshold during any selected portion of a test. This count includes rate number and cumulative number. The selected AE parameters depend on the sensitivity, signal-to-noise ratio, and frequency response of the monitoring system. Thus, the $\mathrm{AE}$ monitoring system should be kept synchronous with the load system.

4.2. Analysis of the AE Characteristics of Samples. The stress curve and AE activity in the failure process of samples are shown in Figure 12. The AE activity of the sample during the loading process was consistent with its stress variation, which could be classified into two categories: brittle failure, which meant the rock samples were damaged immediately upon reaching peak stress, as shown in Figure 12(a); ductile failure, the rock samples damaged gradually after peak stress, as shown in Figures 12(e) and 12(f). 


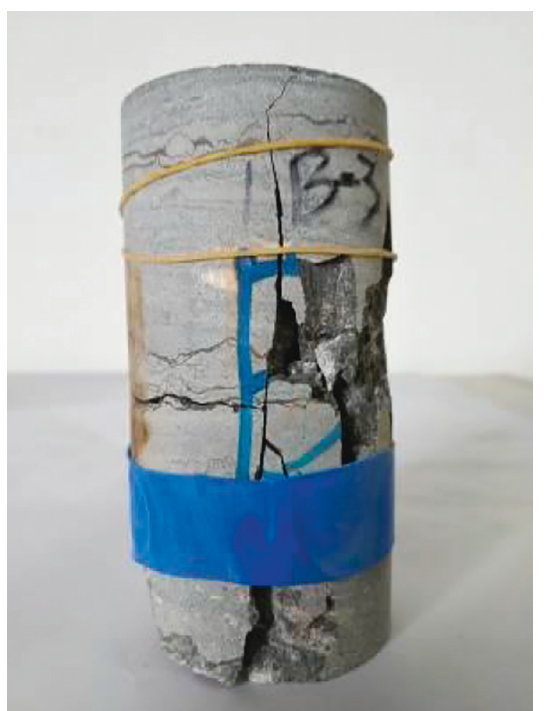

(a)

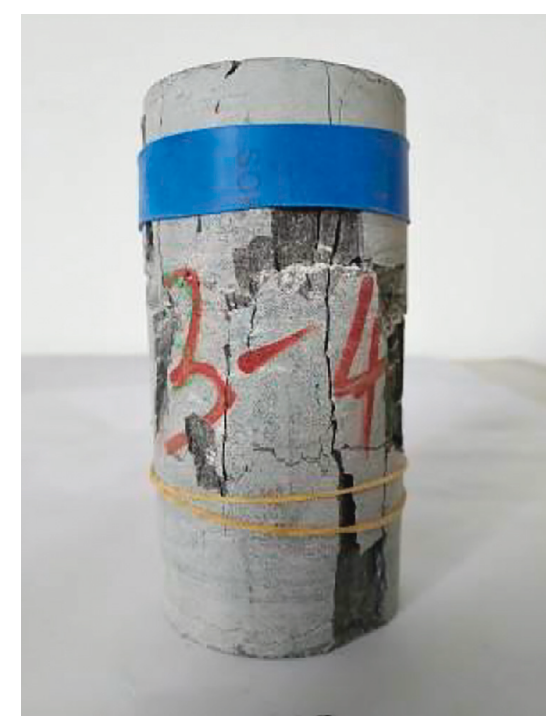

(b)

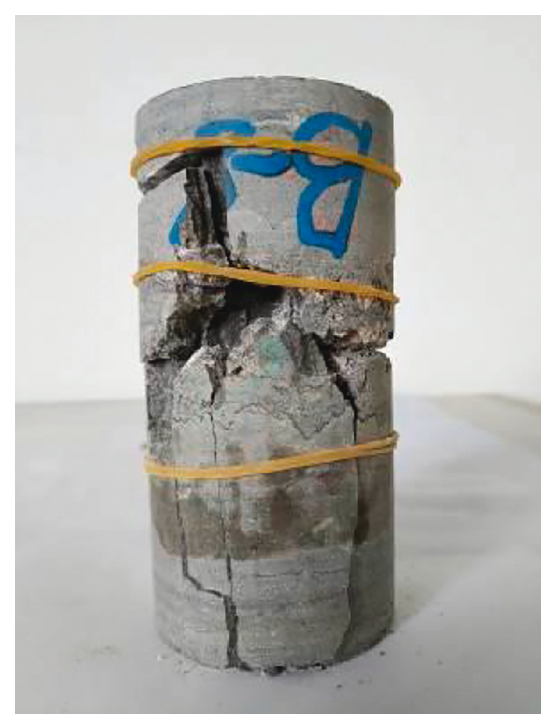

(c)

Figure 10: Failure modes of group B. (a) Dry state. (b) Natural state. (c) Saturated state.

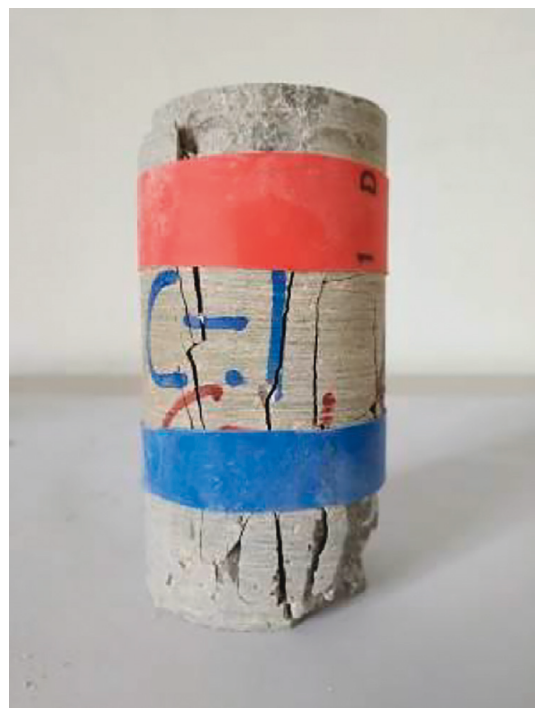

(a)

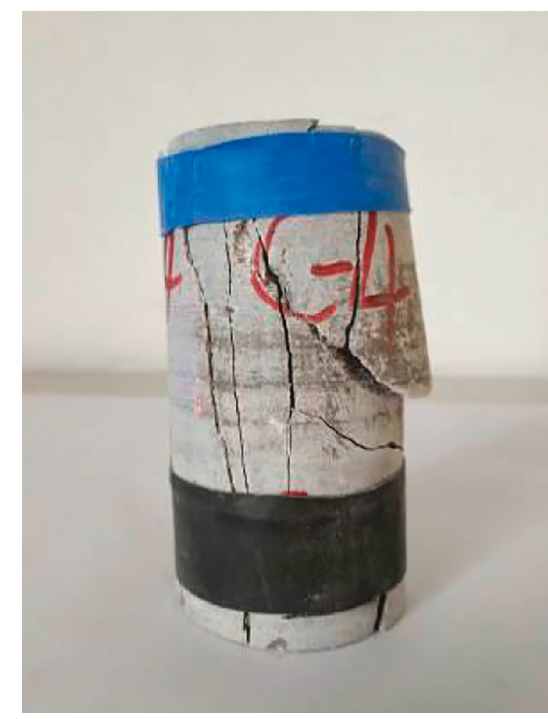

(b)

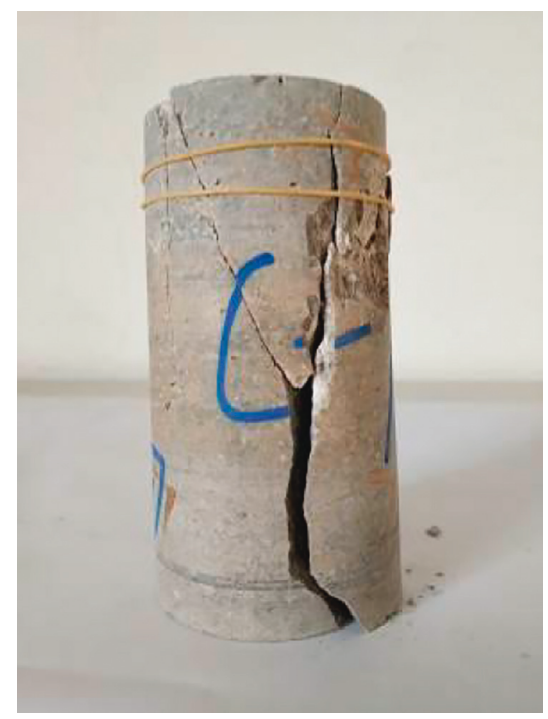

(c)

Figure 11: Failure modes of group C. (a) Dry state. (b) Natural state. (c) Saturated state.

4.2.1. Brittle Failure. After the stages of compaction, elastic deformation, and short plastic deformation (i.e., no obvious plastic deformation was observed), the stress dropped suddenly and the sample was damaged suddenly by bursting fractures. AE activity in the loading process could be divided into the initial stage, slow increase stage, and active and peak stage. The active stage corresponded to the fracture initiation and damage stage. The AE decline stage was not obvious in brittle failure, the sample failed immediately after the $\mathrm{AE}$ peak. Therefore, the AE peak could be used as a sign of sample brittle failure.

4.2.2. Ductile Failure. (1) Initial stage: limited AE activity was generated, which was caused by the crack closure and friction in the compaction process. (2) Slow increase stage: $\mathrm{AE}$ activity increased gradually with the increasing stress loaded, which corresponded to the elastic deformation stage. (3) Active and peak stage: AE activity was about twice of that in the elastic deformation stage and gradually achieved the maximum in the failure process. Compared with brittle failure, the quiet period of $\mathrm{AE}$ activity in ductile failure was not obvious. In this stage, the internal crack propagated and extended quickly, the samples began to produce localization damage, and macrofractures formed. (4) Decline stage: AE activity declined gradually with the decrease of stress. In this stage, macrofractures could be seen on the sample surface. Then the fracturess coalesced, the fracture planes formed, and samples completely damaged. 


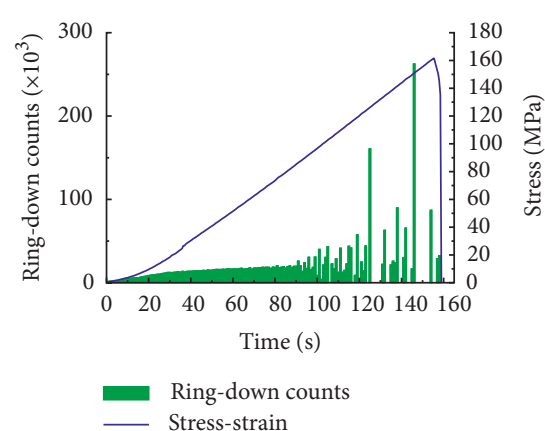

(a)

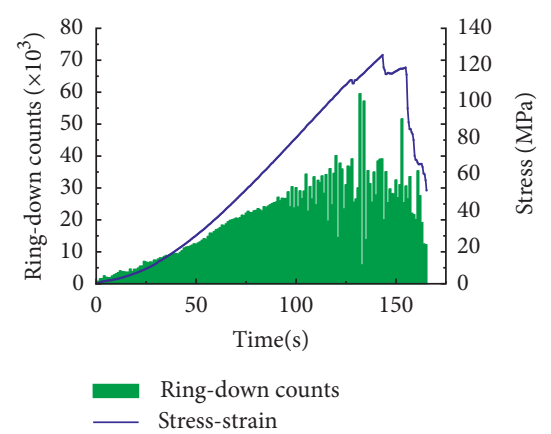

(c)

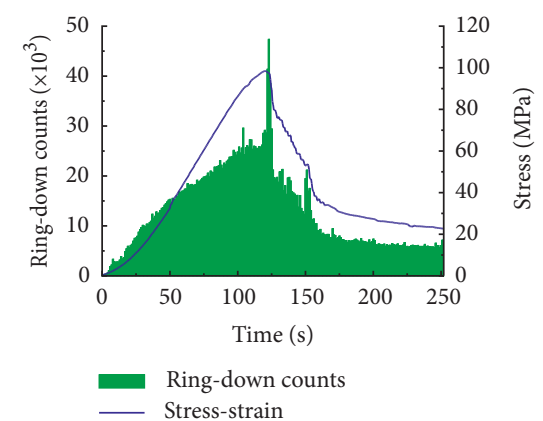

(e)

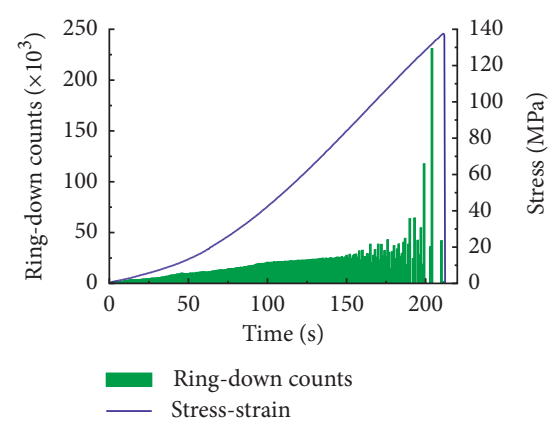

(g)

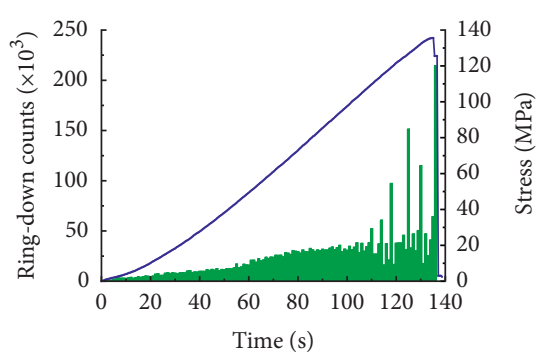

Ring-down counts

Stress-strain

(b)

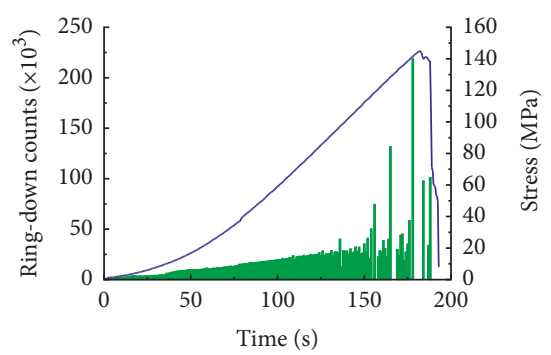

Ring-down counts

(d)

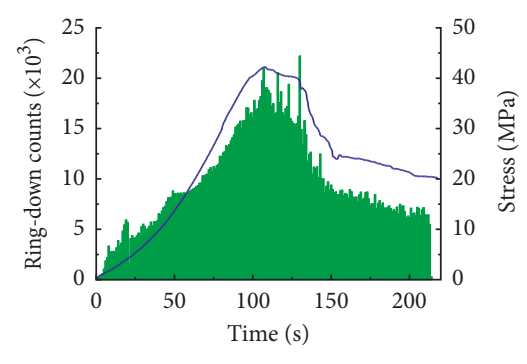

Ring-down counts

(f)

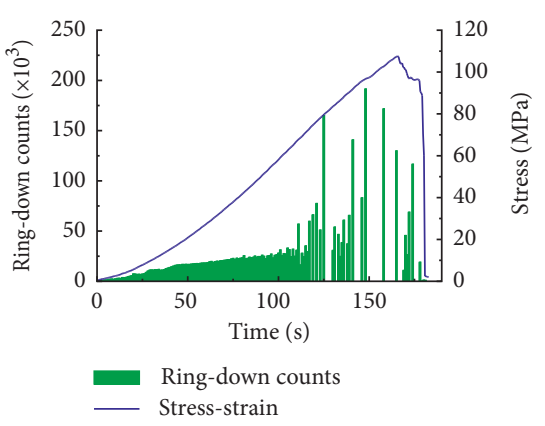

(h)

Figure 12: Continued. 


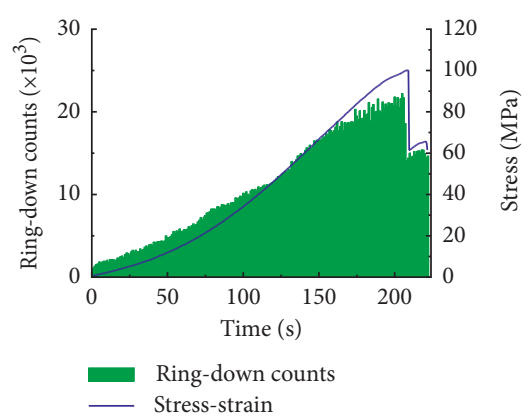

(i)

Figure 12: Stress and AE activity of samples. (a) Group A, dry state (A-1). (b) Group A, natural state (A-4). (c) Group A, saturated state (A-9). (d) Group B, dry state (B-2). (e) Group B, natural state (B-4). (f) Group B, saturated state (B-7). (g) Group C, dry state (C-2). (h) Group C, natural state (C-4). (i) Group C, natural state (C-7).

AE activity decreased dramatically with the increase of water content and decrease of peak strength. When water molecules reached the rock granular space, the contact bond strength of particles reduced, which caused weakening of rock strength at the macro level; meanwhile, pore water pressure can promote the generation of fracture networks during hydraulic fracturing [38-40, 47-49]. For group A, AE peak decreased more than $70 \%$ from dry state to saturated state. For group B, AE peak decreased more than $90 \%$ from dry state to saturated state and decreased about $50 \%$ from natural state to saturated state. For group C, AE peak decreased more than $80 \%$ from dry state to saturated state.

Water content had a significant influence on AE activity. High strength and less water content meant more intense AE activity, but it was not a linear relationship because primary cracks and defects also had major impacts. The coupling effect of water and native defects had a major influence on the fracture initiation and expansion, which caused the macroscopical differences in the evolution characteristics, mechanical properties, and failure modes of $\mathrm{AE}$. Xu et al. [50] thought that the AE activity was seriously affected by the rock type, the structure, and the level of uniformity, and the load mode and load control mode could directly affect the rock failure process, in turn, affect the $\mathrm{AE}$ activity.

From the macro point of view, with the increase of water content, the sample strength and AE peak were reduced significantly. From the microscopic point of view, water affected the formation and expansion of fractures, which caused the change in the mechanical properties and $\mathrm{AE}$ characteristics in the loading process. Figure 13 shows the four main fractures propagation types of karst limestone failure under uniaxial compression in this study.

(1) Vertical tension fractures: These fractures corresponded to elastic-brittle failure, where the AE peak was obvious, indicating the sample failure.

(2) Vertical tension fractures with local shear plane: These fractures mainly belonged to elastic-plasticbrittle failure, where an obvious plastic deformation stage was observed, in which the AE signal was very active. The AE peak in this rupture type was lower than that in elastic-brittle failure.

(3) Shear-tension mixed fractures: These fractures had obvious shear surfaces, which is elastic-plastic-brittle failure. The AE activity increased with the loading, and the AE peak was not obvious.

(4) Spalling of corrosion pores: With the stress centralized around the corrosion pores, the stress-strain curve presented the features of elastic-plastic-ductile failure. The AE peak was not obvious near the peak stress. In the post-peak failure stage, the AE activity reduced gradually with the decrease of stress.

\section{Discussions}

The elastic wave velocity of rock is mainly affected by rock type, density, fissure or interlayer, and water content. Kahraman [51] studied the relationship between the elastic wave velocity and the saturation or porosity of rock based on Gassmann equation and Wood theory. However the study cannot explain the rapid rise of the wave velocity after the saturation threshold. For this reason, Yang et al. [47] considered the influence factors such as gravity and other factors to modify the relation between the wave velocity and the saturation or porosity in the whole process of full water satiety, and the law obtained was consistent with the laboratory test results. For karst limestone with many primary fissures and defects, the wave velocity initially decreased and then increased with the increase of water content, this was similar with Yang et al. [47]. For group C samples with good initial microstructure, the wave velocity increased with the increase of water content; this was similar with Guo et al. [52]. Therefore, the initial microstructure and water content have an important impact on wave velocity. It is noteworthy that the result is static, while elastic wave velocity of rock is changing and shows obvious stage characteristics in the failure process [53]. Therefore, further research on the wave velocity during the whole failure process is needed to study.

The acoustic emission (AE) of rock materials is a phenomenon where rock elastic strain energy is released in the 

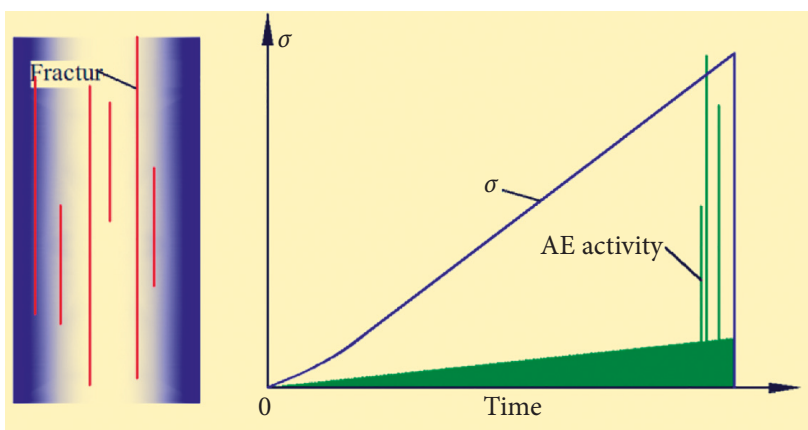

(a)
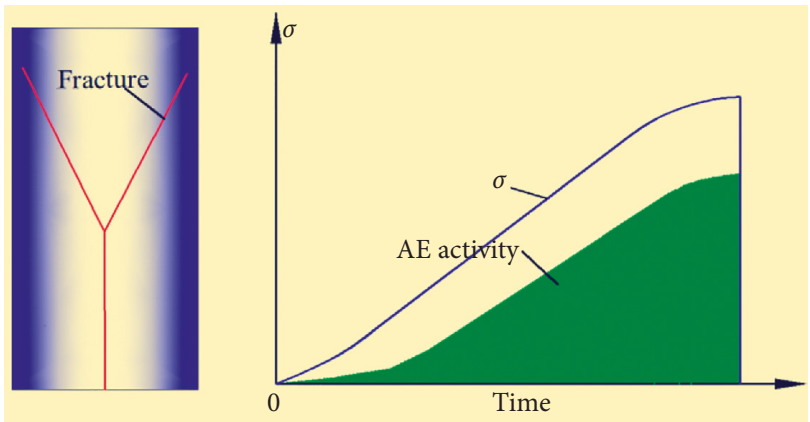

(c)
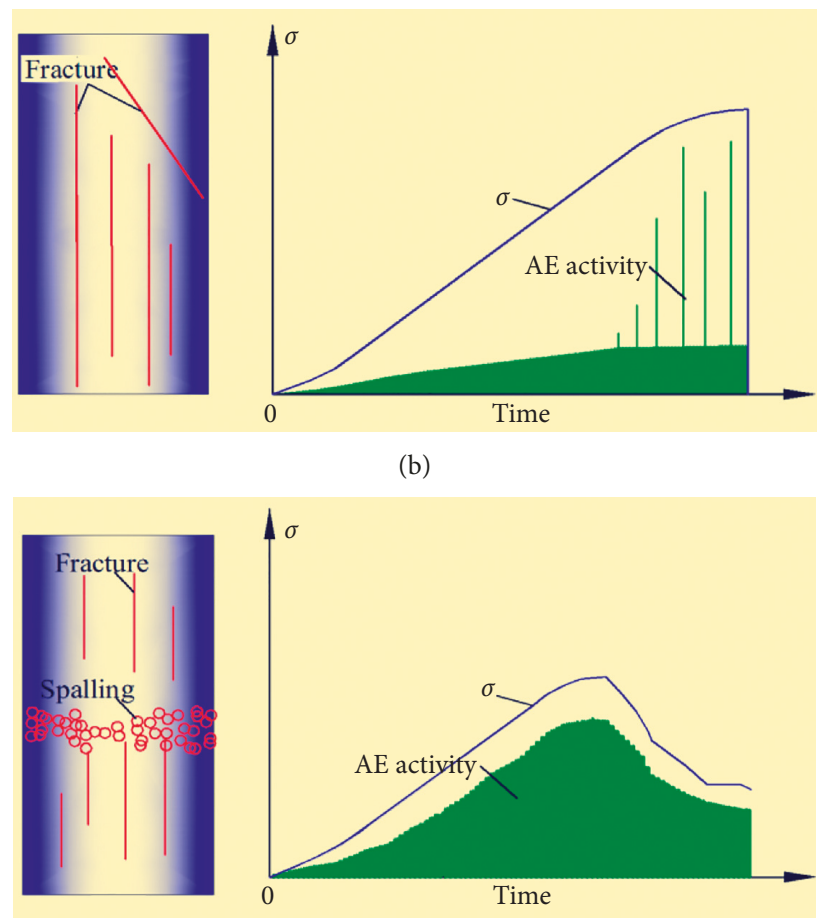

(d)

FIGURE 13: Fracture propagation type and AE characteristic. (a) Vertical tension fractures. (b) Vertical tension fractures with local shear plane. (c) Shear-tension mixed fractures. (d) Corrosion pore spalling.

failure process, and it occurs upon the expansion of internal primary cracks and defects as well as upon the generation or breakage of microcracks under the stress action [54-56]. The results indicated that different initial microstructure and water content cause the difference of mechanical properties and $\mathrm{AE}$ characteristics. On the microscopic level, initial microstructure and water content have an important impact on the cohesion between mineral particles; meanwhile, the pore water pressure can promote fracture initiation and growth. That causes the different number and direction of macroscopic fractures. Therefore, different initial microstructure and water content result in different failure modes, which are corresponding to different $\mathrm{AE}$ characteristic.

Chen et al. [57] showed that the AE characteristics of marble under uniaxial and triaxial compression are different. The confining pressure had a major influence on the mechanical properties and AE characteristics of the rock. Su et al. [58] investigated the AE characteristics of sandstone under different loads by conducting uniaxial compression, conventional triaxial, and triaxial unloading tests. Their results showed that the mechanical properties and $\mathrm{AE}$ characteristics of sandstone were significantly different in different loading modes. The buried depth of a karst tunnel is often large, the ground stress is high. Thus, further research on the AE characteristics of limestone under triaxial compression is required.

\section{Conclusions}

I-RPT ultrasonic detector was first used to test the wave velocity of karst limestone with different initial microstructure and water content. Then RMT-150B rock testing machine and DS2-16B acoustic emission system were used to test the acoustic emission (AE) under uniaxial compression. Mechanical properties and AE characteristics were obtained during rock failure. The detailed relationship between stress-strain and AE characteristics was studied in this paper. Research results indicated the following:

(1) For samples with many primary fissures and defects, wave velocity in dry state was faster than that in its natural state. From natural state to saturated state, the wave velocity tended to increase. For samples with good integrity, wave velocity increased with increasing of water content.

(2) The peak strength of samples decreased with the increase of water content, while the influence of water content on the axial strain and total strain at peak stress was not obvious. In the dry state, the samples presented tension failure with numerous vertical cracks and sheet debris, and the failure degree was serious. In saturated state, the samples presented tension-shear failure. For samples with cracks and good integrity, samples showed brittle failure. For samples with many corrosion pores showed ductile damage under natural and saturated state, and the spalling phenomenon was enhanced under the saturated state.

(3) In brittle failure, the sample failed immediately after the AE peak, which could be used as a sign of sample brittle failure. The AE peak was considerably lower in ductile failure than in brittle failure. For group A, the 
peak count rate decreased more than $70 \%$ from dry state to saturated state. For group B, the peak count rate decreased more than $80 \%$ from dry state to saturated state and reduced about $50 \%$ from natural state to saturated state. For group C, AE peak decreased more than $80 \%$ from dry state to saturated state. The duration of the AE active stage under natural or saturated state was longer and more obvious; this is caused by the water-softening effect that increased the plastic deformation.

(4) Four main crack propagation types of karst limestone failure were observed under uniaxial compression: vertical tension cracks, vertical tension cracks with local shear plane, shear-tension mixed cracks, and spalling of corrosion pores. Four types correspond to different $\mathrm{AE}$ characteristics under uniaxial compression.

\section{Data Availability}

The data used to support the findings of this study are included and showed within the article.

\section{Conflicts of Interest}

All the authors declare that there are no conflicts of interest regarding the publication of this paper.

\section{Acknowledgments}

This work was financially supported by the State Key Development Program for Basic Research of China (Grant no. 2013CB036003) and National Natural Science Foundation of China(Grant nos. 51778215 and 51708040).

\section{References}

[1] Q. Cao, "Study on safe thickness for rock between tunnel and karst cave in karst region," Master's thesis, Beijing Jiaotong University, Beijing, China, 2010.

[2] M. Zhang, Construction Technology of Karst Fault Tunnel in Yichang-Wanzhou Railway, The Science Publishing Company, Beijing, China, 2010.

[3] Y.-B. Luo, J.-X. Chen, Y. Chen, P.-S. Diao, and X. Qiao, "Longitudinal deformation profile of a tunnel in weak rock mass by using the back analysis method," Tunnelling and Underground Space Technology, vol. 71, pp. 478-493, 2018.

[4] Y.-B. Luo, J.-X. Chen, S.-T. Gao, X.-H. Deng, and P.-S. Diao, "Stability analysis of super-large-section tunnel in loess ground considering water infiltration caused by irrigation," Environmental Earth Sciences, vol. 76, no. 22, 2017.

[5] Y.-B. Luo, J.-X. Chen, W.-Z. Xi et al., "Analysis of tunnel displacement accuracy with total station," Measurement, vol. 83, pp. 29-37, 2016.

[6] J.-X. Lai, H.-B. Fan, J.-X. Chen, J.-L. Qiu, and K. Wang, "Blasting vibration monitoring of undercrossing railway tunnel using wireless sensor network," International Journal of Distributed Sensor Networks, vol. 2015, Article ID 703980, 7 pages, 2015

[7] Y.-B. Luo, J.-X. Chen, W.-Z. Xi et al., "Application of a total station with RDM to monitor tunnel displacement," ASCE
Journal of Performance of Constructed Facilities, vol. 31, no. 4, article 4017030, 2017.

[8] Y.-B. Luo, J.-X. Chen, P. Huang, M.-Q. Tang, X. Qiao, and Q. Liu, "Deformation and mechanical model of temporary support sidewall in tunnel cutting partial section," Tunnelling and Underground Space Technology, vol. 61, pp. 40-49, 2017.

[9] Y.-B. Luo, J.-X. Chen, H.-Y. Wang, and P.-L. Sun, "Deformation rule and mechanical characteristics of temporary support in soil tunnel constructed by sequential excavation method," KSCE Journal of Civil Engineering, vol. 21, no. 6, pp. 2439-2449, 2017.

[10] J.-X. lai, J.-L. Qiu, Z.-H. Feng, J.-X. Chen, and H.-B. Fan, "Prediction of soil deformation in tunnelling using artificial neural networks," Computational Intelligence and Neuroscience, vol. 2016, Article ID 6708183, 15 pages, 2016.

[11] http://photo.hanyu.iciba.com/upload/chinesewiki/4/H/4HjD. jpg.

[12] http://pic.sogou.com/d?query=\%CB\%ED\%B5\%C0\%D3\%BF\% CB\%AE\&mode $=1 \&$ did $=504 \#$ did 503 .

[13] http://www.iaozu.com/news/yaozu/2013-11-20/10002.html.

[14] http://pic.sogou.com/d?query=\%D6\%D0\%B9\%FA\%D1\%D2\% C8\%DC\%D4\%D6\%BA\%A6\%B7\%D6\%B2\%BC\%CD\%BC\&mode $=1 \&$ did $=12 \#$ did 11 .

[15] http://www.iaozu.com/d/file/news/yaozu/2013-11-20/d70c9d d82470468b6a4586bce0bb63d8.jpg.

[16] S.-C. Li, Z.-Q. Zhou, L.-P. Li, Z.-H. Xu, Q.-Q. Zhang, and S.-S. Shi, "Risk assessment of water inrush in karst tunnels based on attribute synthetic evaluation system," Tunnelling and Underground Space Technology, vol. 38, pp. 50-58, 2013.

[17] H.-D. Chu, G.-L. Xu, N. Yasufuku, Z. Yu, P.-L. Liu, and J.-F. Wang, "Risk assessment of water inrush in karst tunnels based on two-class fuzzy comprehensive evaluation method," Arabian Journal of Geosciences, vol. 10, no. 7, 2017.

[18] S.-C. Li, J. Wu, Z.-H. Xu, and L.-P. Li, "Unascertained measure model of water and mud inrush risk evaluation in karst tunnels and its engineering application," KSCE Journal of Civil Engineering, vol. 21, no. 4, pp. 1170-1182, 2017.

[19] K. Li, "Initial study of mechanical characteristics of surrounding rock in karst tunnel," M. S. thesis, Southwest Jiaotong University, Chengdu, China, 2005.

[20] J.-Q. Guo, X.-L. Liu, and C.-S. Qiao, "Experimental study of mechanical properties and energy mechanism of karst limestone under natural and saturated states," Chinese Journal of Rock Mechanics and Engineering, vol. 33, no. 2, pp. 296-308, 2014.

[21] L.-P. Li, S.-C. Li, J. Chen et al., "Construction license mechanism and its application based on karst water inrush risk evaluation," Chinese Journal of Rock Mechanics and Engineering, vol. 30, no. 7, pp. 1345-1355, 2011.

[22] Y.-T. Guo, J.-H. Chen, C.-H. Yang, and H.-J. Mao, "Distribution characteristics of rock mechanical parameters for deep drilling sections of carbonate rock in Northeast Sichuan," Rock and Soil Mechanics, vol. 33, no. 1, pp. 161-169, 2012.

[23] Y. Li, Y. Yang, H. Yu, and G. Roberts, "Correlations between the stress paths of a monotonic test and a cyclic test under the same initial conditions," Soil Dynamics and Earthquake Engineering, vol. 101, pp. 153-156, 2017.

[24] T. Katsuyama, Application of Acoustic Emission Technique, China Metallurgical Industry Press, Beijing, China, 1996.

[25] A. M. Farahat and M. Ohtsu, "Evaluation of plastic damage in concrete by acoustic emission," Journal of Materials in Civil Engineering, vol. 7, no. 3, pp. 148-153, 1995.

[26] X.-X. Liu, Z.-Z. Liang, Y.-B. Zhang et al., "Acoustic emission signal recognition of different rocks using wavelet transform 
and artificial neural network," Shock and Vibration, vol. 2015, Article ID 846308, 14 pages, 2015.

[27] T. Xie, H. Qin, R. Chen, and W. Zhang, "Acoustic emission characteristics of rock failure under uniaxial loading," $A d$ vanced Materials Research, vol. 378-379, pp. 43-46, 2011.

[28] G.-Q. Chen, Y. Zhang, R.-Q. Huang, F. Guo, and G.-F. Zhang, "Failure mechanism of rock bridge based on acoustic emission technique," Journal of Sensors, vol. 2015, Article ID 964730, 11 pages, 2015.

[29] Y.-Q. Xiao, Y.-P. Wan, and B.-X. Liu, "Research on landscape limestone damage and deformation under uniaxial compression," Applied Mechanics and Materials, vol. 423, pp. 914-919, 2013.

[30] K.-G. Li, B.-W. Yang, and X.-X. Li, "Effect of native fissures on the mechanical behaviour of rock under uniaxial compression," Tehnicki Vjesnik-Technical Gazette, vol. 24, no. 3, pp. 907-915, 2017.

[31] H. Qin, G. Huang, and W.-Z. Wang, "Experimental study of acoustic emission characteristics of coal samples with different moisture contents in process of compression deformation and failure," Chinese Journal of Rock Mechanics and Engineering, vol. 31, no. 6, pp. 1115-1120, 2012.

[32] E.-E. Damaskinskaya, I.-A. Panteleev, A.-G. Kadomtsev, and O.-B. Naimark, "Effect of the state of internal boundaries on granite fracture nature under quasi-static compression," Physics of the Solid State, vol. 59, no. 5, pp. 944-954, 2017.

[33] S.-Q Yang, H.-W. Jing, and T. Xu, "Mechanical behavior and failure analysis of brittle sandstone specimens containing combined flaws under uniaxial compression," Journal of Central South University, vol. 21, no. 5, pp. 2059-2073, 2017.

[34] Y.-H. Huang, S.-Q. Yang, W.-L. Tian, W. Zeng, and L.-Y. Yu, "An experimental study on fracture mechanical behavior of rock-like materials containing two unparallel fissures under uniaxial compression," Acta Mechanica Sinica, vol. 32, no. 3, pp. 442-455, 2016.

[35] L.-O. Afolagboye, J.-L. He, and S.-J. Wang, "Experimental study on cracking behaviour of moulded gypsum containing two non-parallel overlapping flaws under uniaxial compression," Acta Mechanica Sinica, vol. 33, no. 2, pp. 394-405, 2017.

[36] W.-L. Tian and S.-Q. Yang, "Experimental and numerical study on the fracture coalescence behavior of rock-like materials containing two non-coplanar filled fissures under uniaxial compression," Geomechanics and Engineering, vol. 12, no. 3, pp. 541-560, 2017.

[37] H.-M. Yang, "Study on acoustic emission characterisitic of plastic and brittle coal failure process," Advanced Materials Research, vol. 807-809, pp. 2398-2403, 2013.

[38] Q. Liu, Y.-R. Lu, and X.-Z. Li, "The effect of the pore water pressure on the rock mechanics parameters," Acta Geoscientica Sinica, vol. 25, no. 5, pp. 660-664, 2008.

[39] C.-A. Tang, T.-H. Yang, L.-C. Lian et al., "Numerical simulation to influence of pore pressure magnitude and gradient on fracture propagation in brittle heterogeneous rocks," Rock and Soil Mechanics, vol. 24, pp. 17-20, 2003.

[40] Y. Chen and H. Wang, "Numerical simulation of rock damage process with single hole rock under pore water pressure," Coal Technology, vol. 34, no. 12, pp. 125-128, 2015.

[41] D.-C. Zhang, R.-P. Gamage, M.-S.-A. Perera, C.-P. Zhang, and W.-A.-M. Wanniarachchi, "Influence of water saturation on the mechanical behaviour of low-permeability reservoir rock," Energies, vol. 10, no. 2, 2017.

[42] S. Wu, H.-K. Ge, X.-Q. Wang, and F.-B. Meng, "Shale failure processes and spatial distribution of fractures obtained by $\mathrm{AE}$ monitoring," Journal of Natural Gas Science and Engineering, vol. 41, pp. 82-92, 2017.

[43] L. Chen, J. Zhao, and Z.-Y. Zheng, "Acoustic emission characteristics of compressive deformation and failure of siltstone under different water contents," Advances in Materials Science and Engineering, vol. 2017, Article ID 4035487, 13 pages, 2017.

[44] E.-Z. Lajtai, B.-J. Carter, and M.-L. Ayari, "Criteria for brittle fracture in compression," Engineering Fracture Mechanics, vol. 37, no. 1, pp. 59-74, 1990.

[45] J.-S. Kim, K.-S. Lee, W.-J. Cho, H.-J. Choi, and G.-C. Cho, “A comparative evaluation of stress-strain and acoustic emission methods for quantitative damage assessments of brittle rock," Rock Mechanics and Rock Engineering, vol. 48, no. 2, pp. 495-508, 2015.

[46] B. Lee and T.-D. Rathnaweera, "Stress threshold identification of progressive fracturing in Bukit Timah granite under uniaxial and triaxial stress conditions," Geomechanics and Geophysics for Geo-Energy and Geo-Resources, vol. 2, no. 4, pp. 301-330, 2016.

[47] W.-M. Yang, J. Song, B. Liu et al., "Experimental research on wave velocity and electrical resistivity of rock-like material during saturation process," Chinese Journal of Rock Mechanics and Engineering, vol. 34, no. 4, pp. 704-712, 2015.

[48] G.-Q. Chen, T.-B. Li, F. Guo, and Y.-K. Wang, "Brittle mechanical characteristics of hard rock exposed to moisture," Bulletin of Engineering Geology and the Environment, vol. 76, no. 1, pp. 219-230, 2017.

[49] F.-B. Meng, H.-K. Ge, W. Yan, X.-Q. Wang, S. Wu, and J.-B. Wang, "Effect of saturated fluid on the failure mode of brittle gas shale," Journal of Natural Gas Science and Engineering, vol. 35, pp. 624-636, 2016.

[50] J. Xu, S.-C. Li, X.-J. Tang, Y.-Q. Tao, and Y.-D. Jiang, "Influential factors of acoustic emission location experiment of rock under uniaxial compression," Chinese Journal of Rock Mechanics and Engineering, vol. 27, no. 4, pp. 765-772, 2008.

[51] S. Kahraman, "The correlations between the saturated and dry P-wave velocity of rocks," Ultrasonics, vol. 46, no. 4, pp. 341-348, 2007.

[52] J.-Q. Guo, Z.-L. Xu, and H.-F. Hong, "Influence of watersaturated state on mechanical properties and longitudinal wave velocity of karst limestone," Journal of Civil, Architectural and Environmental Engineering, vol. 37, no. 2, pp. 60-66, 2015.

[53] H.-R. Li, C.-H. Yang, Y.-G. Liu et al., "Experimental study of ultrasonic velocity and acoustic emission properties of salt rock under uniaxial compression load," Chinese Journal of Rock Mechanics and Engineering, vol. 33, no. 10, pp. 21082116, 2014.

[54] Q.-B. Meng, M.-W. Zhang, L.-J. Han, H. Pu, and Y.-L. Chen, "Acoustic emission characteristics of red sandstone specimens under uniaxial cyclic loading and unloading compression," Rock Mechanics and Rock Engineering, vol. 51, no. 4, pp. 969-988, 2018.

[55] D.-Q. Liu, Z. Wang, X.-Y. Zhang et al., "Experimental investigation on the mechanical and acoustic emission characteristics of shale softened by water absorption," Journal of Natural Gas Science and Engineering, vol. 50, pp. 301-308, 2018.

[56] P. Ganne, A. Vervoort, and M. Wevers, "Quantification of pre-peak brittle damage: Correlation between acoustic emission and observed micro-fracturing," International Journal of Rock Mechanics and Mining Sciences, vol. 44, no. 5, pp. 720-729, 2007. 
[57] Z.-Q. Chen, C. He, D. Wu, G.-W. Xu, and W.-B. Yang, "Fracture evolution and energy mechanism of deep-buried carbonaceous slate," Acta Geotechnica, vol. 12, no. 6, pp. 1243-1260, 2017.

[58] C.-D. Su, B.-B. Gao, H. Nan, and X.-J. Li, "Experimental study on acoustic emission characteristics during deformation and failure processes of coal samples under different stress paths," Chinese Journal of Rock Mechanics and Engineering, vol. 28, no. 4, pp. 757-766, 2009. 


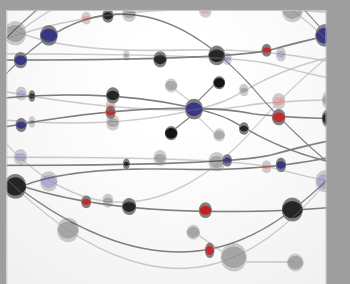

The Scientific World Journal
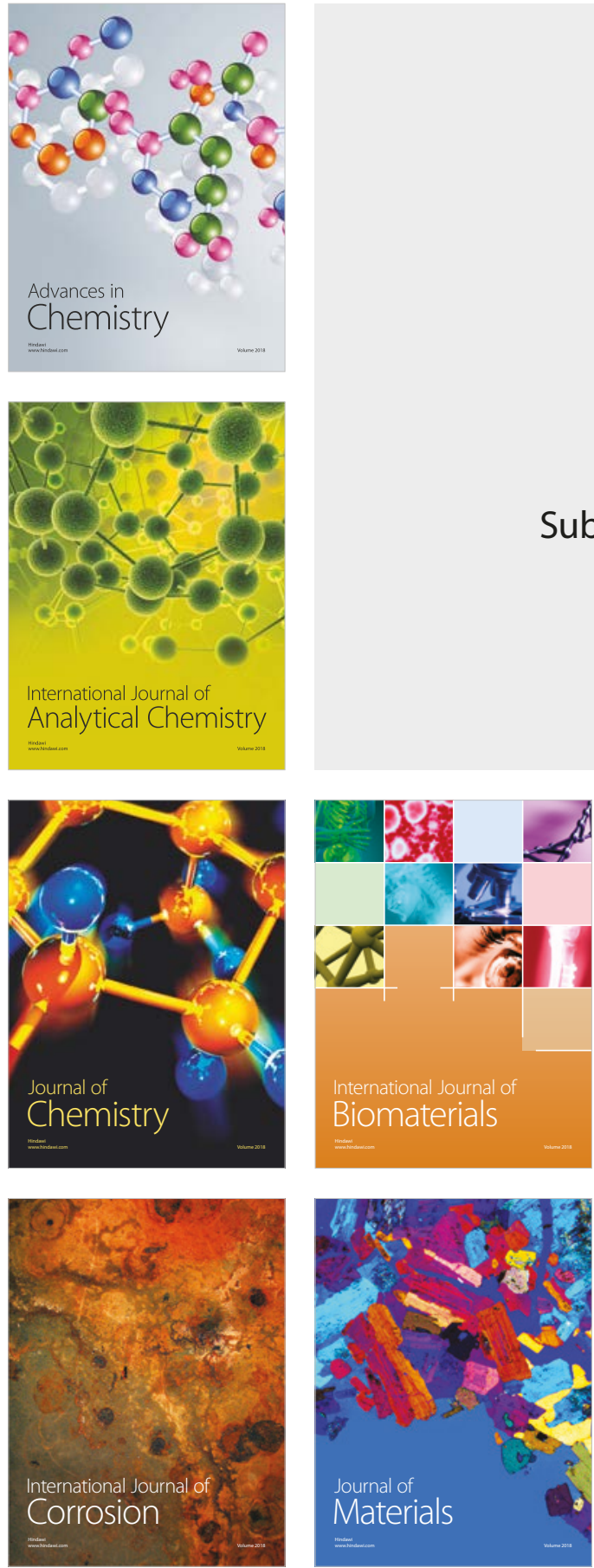

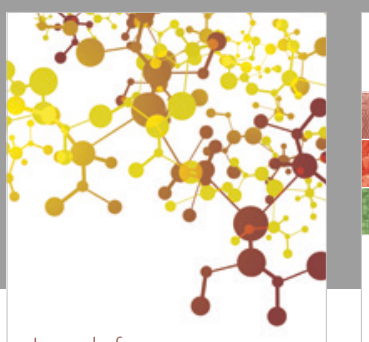

Journal of

Applied Chemistry
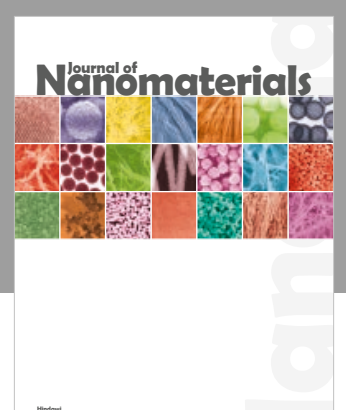

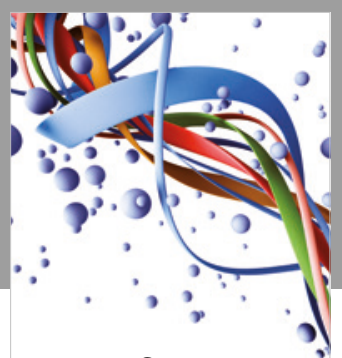

Scientifica

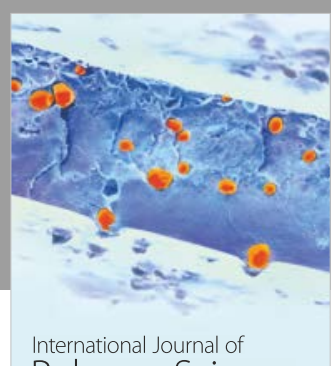

Polymer Science

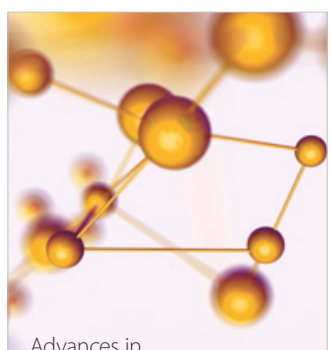

Physical Chemistry
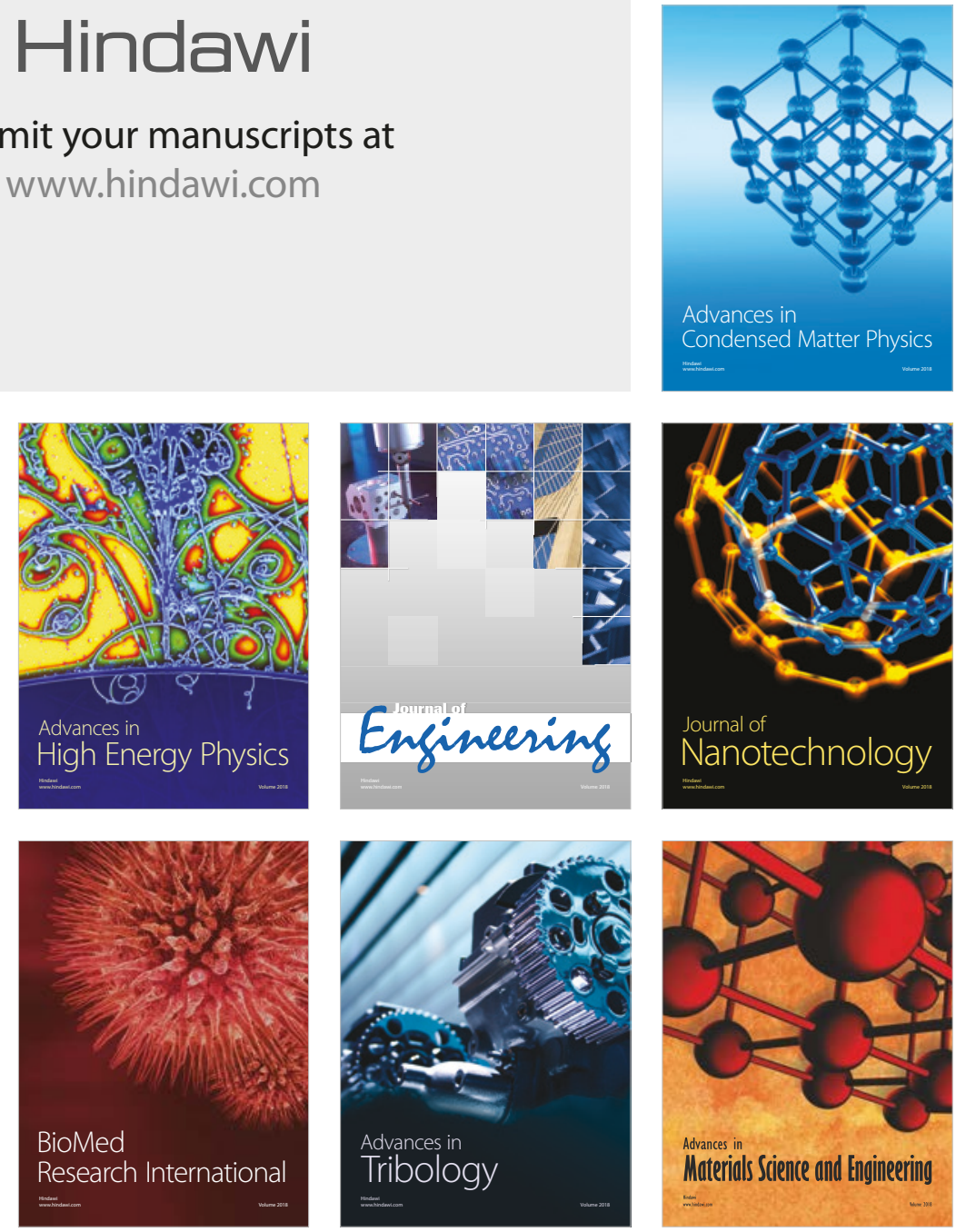